\title{
Joint interaction with embedded concretions: joint loading configurations inferred from propagation paths
}

\author{
David T. McConaughy ${ }^{1}$, Terry Engelder* \\ Department of Geosciences, The Pennsylvania State University, University Park, PA 16802, USA
}

Received 16 December 1997; accepted 18 May 1999

\begin{abstract}
The interaction between propagating joints and embedded concretions in a Devonian black shale near Seneca Lake, NY, permits identification of the loading configurations responsible for two joint sets of different ages striking at nearly the same orientation. The earlier set consists of systematic joints cut by later Alleghanian joints of the Appalachian Plateau. The later set consists of non-systematic curving cross joints that abut these same Alleghanian joints. Field evidence shows that concretions functioned as stiff inclusions in a compliant black shale. As a consequence of this elastic contrast, local perturbations in the remote stress field persisted around the concretions during burial, tectonic deformation, and exhumation. These stress perturbations influenced joint propagation paths of both joint sets. Our conclusions about loading configurations are based on finite-element modeling of the effect of the local stress perturbation on concretion-modified joint propagation. Modeling shows that the local stress perturbation from a thermoelastic loading was responsible for deflecting cross joints away from concretions in a curved propagation path near the concretion. This load configuration also led to arrest of cross joints before they penetrated the shale-concretion interface. At greater distances from the concretion, the propagation path of cross joints was controlled by the contemporary tectonic stress field. The interface between concretions and the surrounding shale was strongly bonded, as indicated by the crossing of the interface by some of the systematic ENE joints. Higher compressive stress levels within the concretions relative to the shale suppressed joint development in the concretion, causing the arrest of those joints once they had driven across the interface and a short distance into the concretion. Numerical modeling shows that interface penetration by the systematic ENE joints is consistent with a fluid load, the same loading configuration postulated for the subsequent Alleghanian joints. The traces of the systematic ENE joints align on opposite sides of concretions, rather than curving toward the concretion as predicted by two-dimensional models of the fluid load. Co-planar traces are indicative of large, planar joints propagating in-plane around the concretion, making it energetically inefficient for the crack front to curve as it enters the local stress perturbation near the concretion. A fluid load for the systematic ENE joints came from high pore pressure during the pre-Alleghanian stages of burial of the Devonian Catskill delta complex. (C) 1999 Elsevier Science Ltd. All rights reserved.
\end{abstract}

\section{Introduction}

Joints are driven in response to any of at least four loading configurations in the Earth: a joint-normal load, a thermoelastic load, a fluid load, and an axial load (Engelder and Fischer, 1996). Identification of the loading configuration responsible for systematic joints

\footnotetext{
* Corresponding author.

E-mail address: engelder@geosc.psu.edu (T. Engelder)

${ }^{1}$ Now at Shell Offshore Inc., New Orleans, LA 70161, USA.
}

is aided by an analysis of joint surface morphology (e.g. Lacazette and Engelder, 1992). However, joints in shale are usually without any distinguishing surface morphology and thus more difficult than joints in siltstone to diagnose for loading configuration. This is the case for a systematic ENE joint set [i.e. the strike joint set of Sheldon (1912), also called set III joints by Parker (1942)] best developed in Devonian black shales of the Finger Lakes District of the Appalachian Plateau, NY.

The discovery that the systematic ENE joints did not propagate completely through concretions gave us 


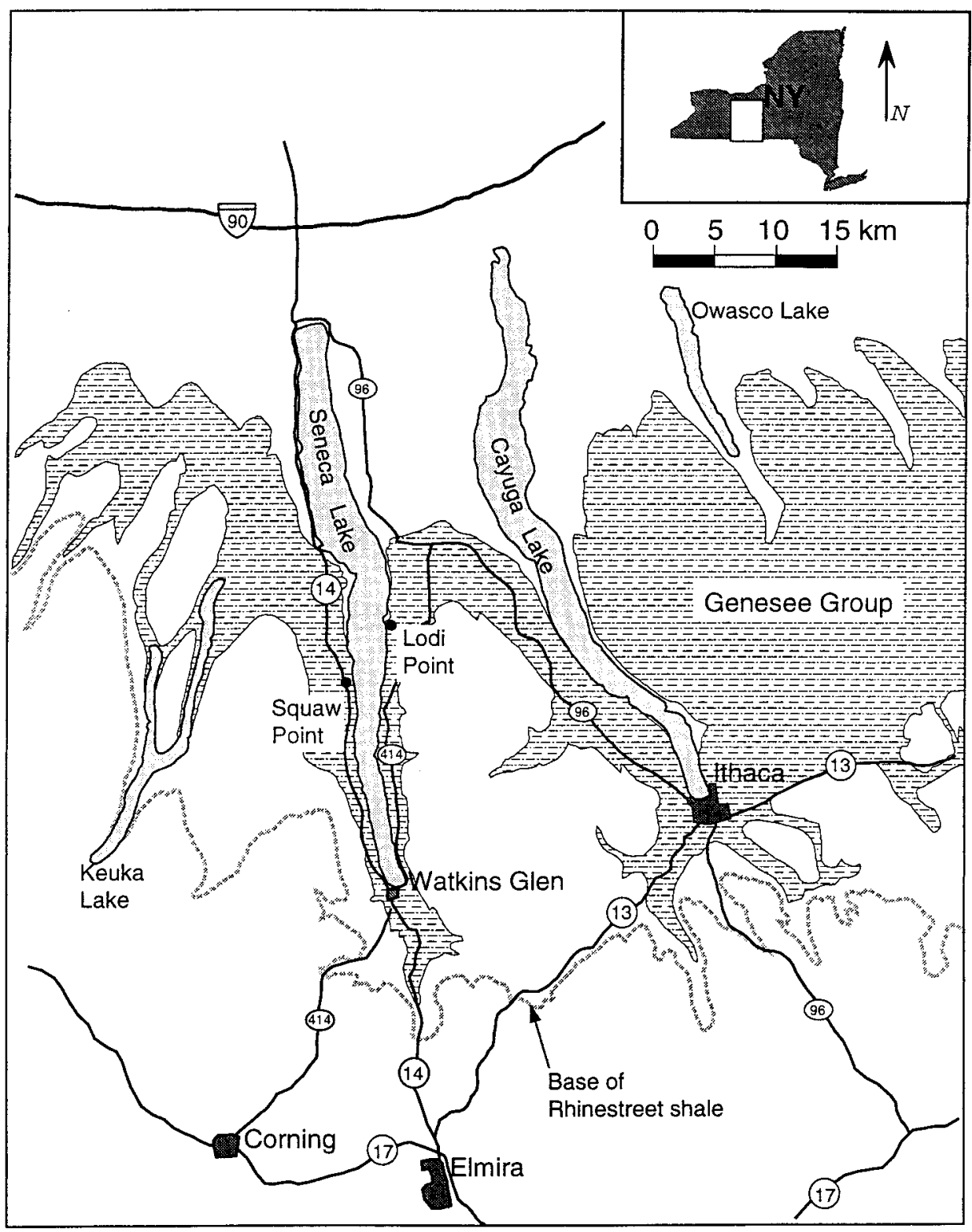

Fig. 1. Outcrops containing siderite concretions at Squaw Point and Lodi Point, Finger Lakes district, NY. Stream channels along Seneca Lake cut down into the black shales of the Geneseo Formation, the basal unit in the Upper Devonian Genesee Group. The base of the Rhinestreet Formation (dashed line), marks the postulated location of a pre-Alleghanian pressure seal that contributed to the formation of the systematic ENE joints.

the idea that the joint-concretion interaction may hold information on the loading configuration at the time of joint propagation. This idea was reinforced with the discovery of a second type of ENE-striking joint, one with curved joint propagation paths in the vicinity of concretions embedded in black shale. Our idea was that the presence of the concretions created a local perturbation in the remote stress field that influenced the direction of joint propagation. In addition, the stress contrast between the shale and embedded concretion under various loading configurations controls whether or not the joints penetrated from the black shale into the concretion.

This study investigates two possible loading configurations for the formation of two distinct types of ENE-striking joints in the Devonian black shales of the Appalachian Plateau. One configuration is a thermoelastic load, under which the rock mass is subject to tensile stress and joints are driven by a mechanism called elastic contraction (Engelder and Fischer, 1996). The second loading configuration requires the development of fluid pressure within a joint that exceeds the 
least horizontal stress. Under this latter configuration, natural hydraulic fractures propagate in response to a fluid load (e.g. natural gas, oil, water) on the inside of a flaw such as a large pore, crack, or small joint (i.e. Engelder and Lacazette, 1990) as well as within matrix pore space (i.e. Miller, 1995). For natural hydraulic fractures, fluid decompression is the driving mechanism where the energy for formation of new joint surface area is released from the potential energy of the driving fluid as its pressure drops (Lacazette and Engelder, 1992; Engelder and Fischer, 1996). Previously, the case for fluid decompression as a driving mechanism in the formation of systematic joints was based on incremental crack growth as displayed on joint surface morphology in siltstones. Our analysis of joint propagation in the vicinity of concretions in a Devonian black shale of the Appalachian Plateau provides additional evidence for joint growth driven by fluid loading despite lack of corroborating surface morphology.

Finite-element techniques are used to model the propagation of joints under boundary conditions that approximate two joint-loading configurations: a fluid load and a thermoelastic load. The response of the modeled joints to local perturbations in the stress field caused by the concretions is used to infer the conditions under which the two types of natural joints propagated within the Devonian black shales. This paper was motivated by the desire to identify the loading configuration leading to the systematic ENE joints in black shale of the Finger Lakes District, Appalachian Plateau.

\section{Field observations}

Streams near Squaw Point on the western shore and Lodi Point on the eastern shore of Seneca Lake, NY, cut down into the black shales of the Geneseo Formation (Fig. 1). The Geneseo Formation is the basal unit of the Upper Devonian Genesee Group, part of the Catskill Delta complex deposited during the Acadian Orogeny (Ettensohn, 1985). The Geneseo Formation is a homogeneous black shale, about $30 \mathrm{~m}$ thick in the study area, that crops out in an E-Wtrending band across the central Appalachian Plateau of New York. Systematic ENE and Alleghanian joint sets are well-developed within the Geneseo black shales. The more closely spaced ENE set strikes $075^{\circ}$ at Squaw and Lodi Points. Alleghanian joints strike approximately $336^{\circ}$ intersecting the systematic ENE joints nearly at right angles (Engelder and Geiser, 1980). As is the case elsewhere on the Plateau, the two sets mutually cross-cut one another with no sign of interaction. Slip on the Alleghanian joints offsets the
ENE set indicating that the ENE set is preAlleghanian (Engelder et al., submitted).

The black shales of the Geneseo Formation contain approximately $1.5 \%$ total organic carbon (TOC) compared to an average of $0.5 \%$ TOC in the Devonian gray shales of the Catskill Delta complex (Engelder et al., submitted). The elevated organic content and reducing environment characteristic of black shales contribute to the formation of siderite concretions that grow relatively early in the diagenetic history of the shale (Oertel and Curtis, 1972). Exposed within several stream beds of the area are rounded siderite concretions that have influenced the local development of joints (Fig. 2). In the case of the two concretions shown in Fig. 2, the more widely spaced Alleghanian joints do not intersect either of the concretions, whereas the systematic ENE joints generally abut them (Fig. 2). Close examination reveals that several systematic ENE joints propagated without deviating from their plane a few centimeters into the larger concretion before arresting. In rare cases systematic ENE joints curve toward the concretion to abut the normal to its surface. If a concretion is small enough a systematic ENE joint may cut off an edge (Fig. 2).

A number of shorter ENE-striking joints curve in the immediate vicinity of the concretions. These behave like cross joints, abutting earlier Alleghanian joints and terminating against concretions and are, thus, different from the systematic ENE joints. Cross joints are aligned sub-parallel to the systematic ENE joints but curve away from the concretion as they approach it such that the joints become tangent to the perimeter of the concretions (Fig. 2). Both systematic ENE joints and cross joints are found interacting with other concretions in the study area including those at Lodi Point.

The Squaw Point outcrop offers an opportunity to examine in detail the effect of a spherical inclusion on the propagation paths of two different types of joints. As they approach the concretions, the joint traces of both the systematic ENE joints and the cross joints are diagnostic of joint propagation under different loading configurations (cf. Engelder and Fischer, 1996). The more widely spaced Alleghanian joints do not interact with the concretions in this outcrop or at Lodi Point and are not part of the analysis.

\section{Modeling cross-joint propagation}

The curving propagation paths of the cross joints in the immediate vicinity of a concretion suggest that their development was affected by stress perturbations associated with the concretion. A series of models were constructed to investigate joint propagation near a concretion using FRacture ANalysis Code (FRANC), 
(a)

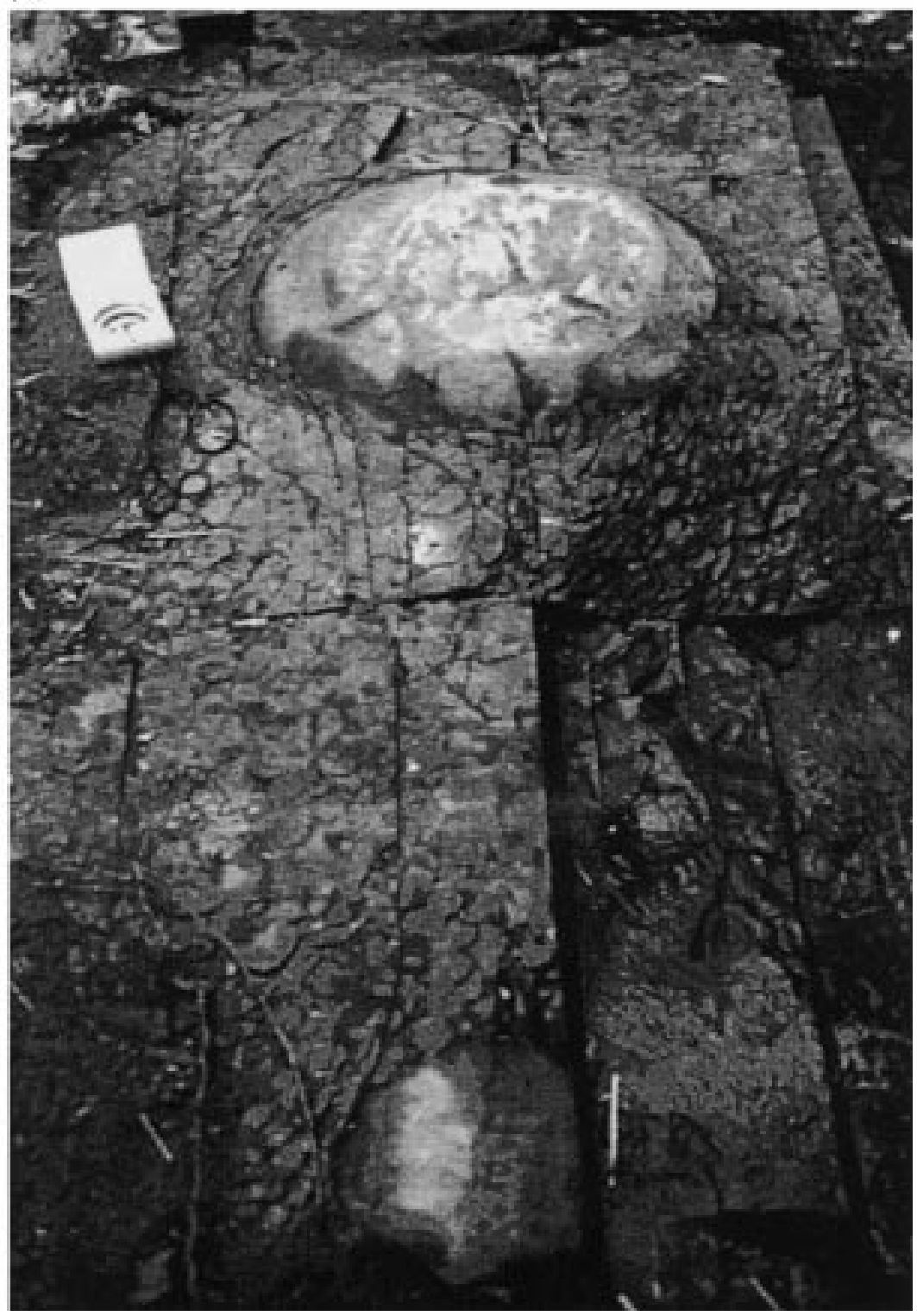

Fig. 2. (a) Field photograph showing the interaction between joints and two concretions embedded in the black shale of the Geneseo Formation. The larger concretion is approximately $40 \mathrm{~cm}$ in diameter (note compass for scale). (b) (On facing page.) Drawing of the field photograph highlighting the joint traces and cross-cutting relationships. The outcrop contains two systematic joint sets: an Alleghanian set oriented at $336^{\circ}$, and a nearly orthogonal set of $075^{\circ}$ joints. Also present are non-systematic cross joints that abut the systematic joints and curve in the vicinity of the concretions.

a finite-element code developed at Cornell University (Wawrzynek and Ingraffea, 1987) that is specifically designed to analyze two-dimensional crack propagation problems. FRANC has been successfully used to apply the principles of linear elastic fracture mechanics to a variety of geologic problems, including the modeling of fluid-driven joints (Fischer et al., 1995). Numerical modeling, using FRANC, follows Fischer et al. (1995) in the application of boundary conditions to simulate environments in which joints propagate under either of two loading configurations: a joint-normal thermoelastic load producing a tensile stress, or a fluid load producing an effective tensile stress (Engelder and Fischer, 1996). Near-surface thermoelastic loading conditions are approximated by applying uniform extensional strain to elastic, isotropic media, producing a tensile stress field that is locally perturbed near structures such as joints or inclusions. Conditions appropriate for the formation of joints at depth are produced by applying uniform biaxial contractional strains, thereby generating a compressive stress field about joints. This stress field represents the total stresses that result from external loading and the poroelastic response of the rock to fluid pressure. Fluid-driven 


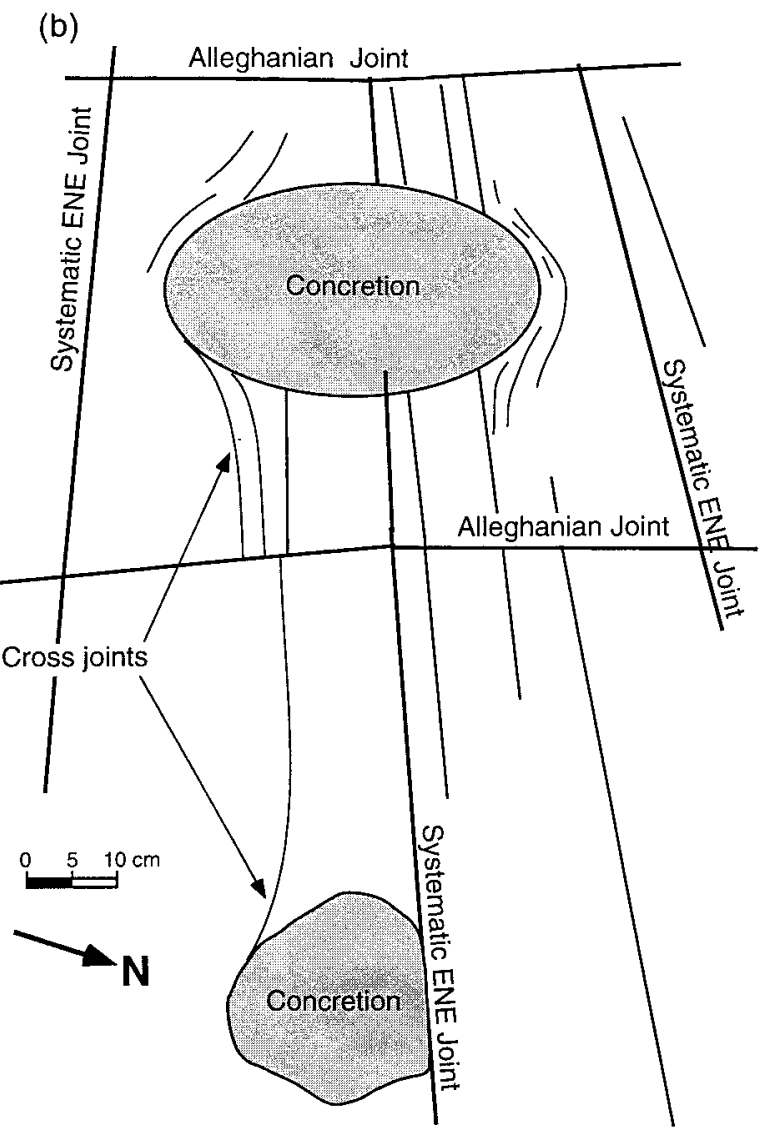

Fig. 2. (continued).

joints are simulated by applying uniform internal fluid pressure, in excess of the total remote compressive stress, to the walls of a pre-existing fracture. Fischer (1994) verified the appropriateness of the two sets of boundary conditions for elastic models containing joints by finding good agreement between finiteelement solutions for one-dimensional variation in joint normal stress with distance away from the wall of a joint and existing analytical solutions (Lachenbruch, 1961; Pollard and Segall, 1987). These boundary conditions are used to model local stress perturbations around stiff inclusions (e.g. concretions), and to model joint propagation within the stress shadow of the concretions. A finite element approach is used to follow the evolving stress pattern as the fracture grows into the stress perturbation caused by the concretion.

The goal of modeling the propagation of cross joints was to answer the following questions: How is the stress field modified by the presence of a concretion? Could the resulting stress perturbation deflect cross joints in a manner similar to that observed at the Squaw Point outcrop? What does the curved path of a

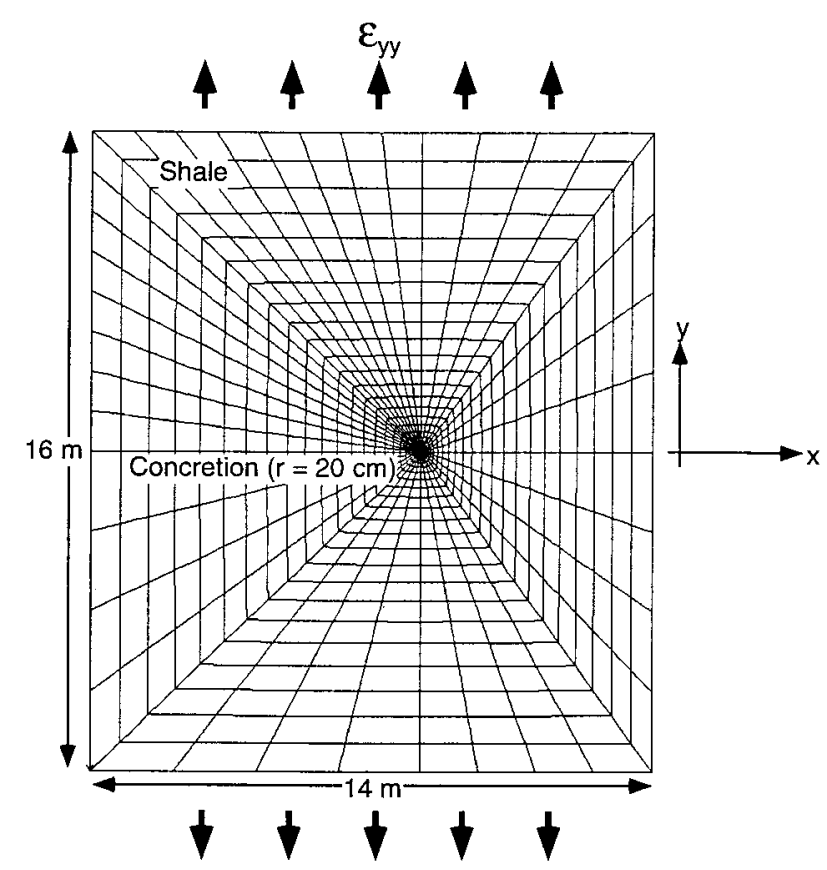

Fig. 3. Two-dimensional propagation of vertically oriented joints is modeled in a horizontal cross-section through the center of a spherical concretion. The model configuration, finite-element mesh, and boundary conditions for two-dimensional modeling of crack propagation in the horizontal plane are as shown. The model contains two material domains, a carbonate concretion (radius $=20 \mathrm{~cm}$, $E=25-50 \mathrm{GPa}, v=0.16$ ), and the surrounding shale $(E=16 \mathrm{GPa}$, $v=0.16$ ). The concretion and the shale are bonded perfectly to one another. An imposed strain applied under plane strain conditions produces a tensile stress field.

joint indicate about the nature of the joint driving mechanism?

\subsection{Model geometry and boundary conditions}

The natural system to be modeled consists of a spherical concretion, $40 \mathrm{~cm}$ in diameter, surrounded by an homogeneous shale (Fig. 3). The propagation of vertical fractures in the shale is modeled in a horizontal cross-section through the center of the concretion. The geometry is specified in Cartesian coordinates with the origin $(0,0)$ located along a diameter at the perimeter of the concretion. The model contains two material domains for which elastic properties are prescribed (Fig. 3). A comparison of representative elastic moduli for shale vs carbonate indicates that the concretion should have a higher Young's modulus than the shale (Fischer, 1994). Slickenlines in shales surrounding similar concretions at Bear Valley Strip Mine, Shamokin, PA, suggest that shale was extruded around the concretions during folding. This provides evidence for the role of the concretions as stiff inclusions during deformation after both the concretion and surrounding shale have lithified (Nickelsen, 1979). Model runs were conducted using a Young's modulus 


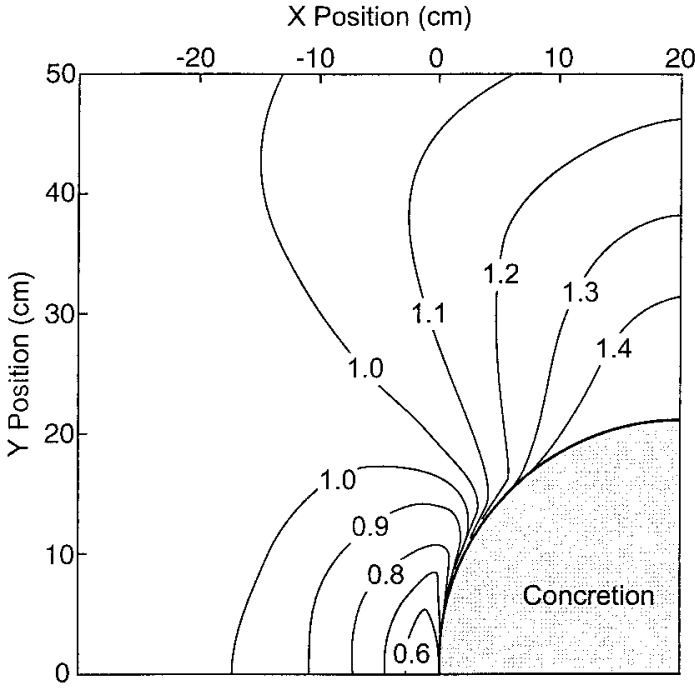

Fig. 4. Contour map of the normalized $\left(\sigma_{y y} / \sigma_{y y}^{\mathrm{r}}\right)$ tensile stress field produced by extensional loading prior to introduction of a joint. Imposed strain $\left(\epsilon_{y}\right)$ of $6.25 \times 10^{-4}$ produces a theoretical remote tensile stress $\left(\sigma_{y y}^{\mathrm{r}}\right)$ of $10.26 \mathrm{MPa}$ in the shale. The presence of the stiffer concretion generates stress shadows, regions of elevated stress along the $y$-axis and reduced tensile stress about the $x$-axis. The stress field is symmetrical about the center of the concretion. Stress within the concretion is uniform and approximately $40 \%$ higher than the remote stress. This figure is a magnification of the central portion of Fig. 3.

of $16 \mathrm{GPa}$ for the shale, and values of 25-50 GPa for the concretion. A Poisson's ratio of 0.16 was assigned to the shale and values from 0.16 to 0.25 to the concretion. Fracture toughness $\left(K_{\mathrm{Ic}}\right)$ for the shale was considered to be $0.9 \mathrm{MPa} \mathrm{m}^{1 / 2}$. Fractures were not permitted to propagate into the concretion, making estimation of $K_{\mathrm{Ic}}$ for the concretion unnecessary.

\subsection{Results: thermoelastic loading}

To approximate a thermoelastic load, the model was subjected to a uniform extensional strain $\left(\epsilon_{y}\right.$, Fig. 3) of $6.25 \times 10^{-4}$. This produced a calculated tensile stress $\left(\sigma_{y y}\right)$ at the boundaries of the model with a maximum difference of $1.5 \%$ from the theoretical remote stress $\left(\sigma_{y y}^{\mathrm{r}}\right)$ of $10.26 \mathrm{MPa}$ expected for a uniform material domain $(E=16 \mathrm{GPa}, v=0.16)$. The stress within the concretion was uniform (within 1\%), as expected for a circular inclusion (Eshelby, 1957). The contrast in moduli $\left(E_{\text {shale }}=16 \mathrm{GPa}, E_{\text {concretion }}=50 \mathrm{GPa}\right)$ caused $\sigma_{y y}$ within the concretion to be $40 \%$ higher than the remote stress in the shale.

A contour plot of normalized stress $\left(\sigma_{y y} / \sigma_{y y}^{\mathrm{r}}\right)$ around the concretion, prior to introduction of a joint, shows the stress perturbation associated with the concretion (Fig. 4). It is similar in geometry, but opposite in sign, to those associated with a circular hole in an elastic medium. Regions of elevated tensile stress in the shale are symmetrical about the center of the concretion in

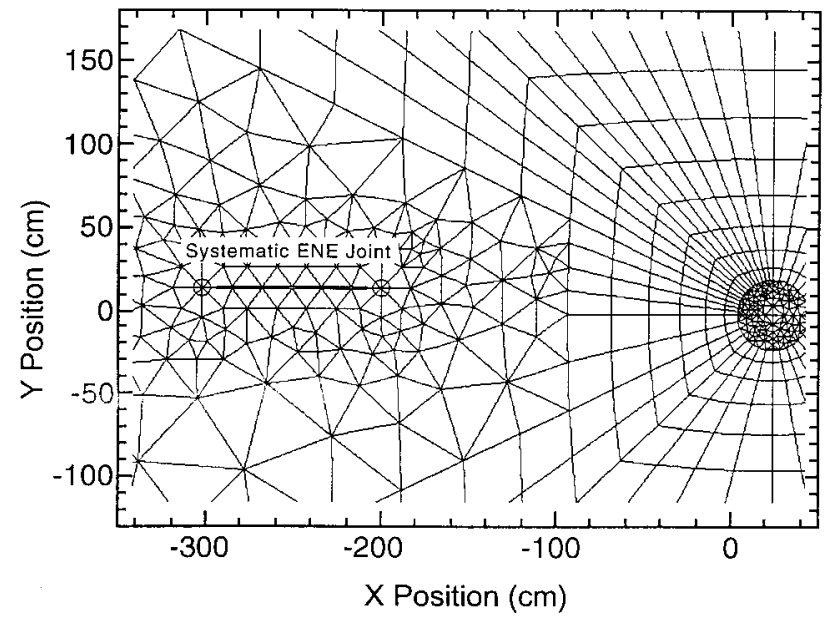

Fig. 5. Detail of the finite-element mesh showing placement of the initial joint. A 1-m-long joint is positioned with its nearer crack-tip $2 \mathrm{~m}$ from the concretion (crack-tip coordinates [(-3.0, 0.15), $(-2.0$, $0.15)]$ ). Simulations were performed in which the crack position along the $y$-axis was varied from $y=0$ to $20 \mathrm{~cm}$ ( $y=15 \mathrm{~cm}$ shown).

the $y$-direction. Similarly, regions of reduced tensile stress are distributed symmetrically along the $x$-axis immediately outside the perimeter of the concretion.

Because the nature of the initiation of the joints (initial size, location, and orientation of the flaw) is unknown, the analysis places a 1-m-long joint oriented perpendicular to the least principal stress $\left(\sigma_{y y}^{\mathrm{r}}\right)$, with its tips positioned at the coordinates $[(-3.0,0.15)(-2.0$, $0.15)$ ], such that the nearer crack-tip was $2 \mathrm{~m}$ from the concretion (Fig. 5). The joint driving stress $(\Delta \sigma)$ in this loading configuration is equal to the local tensile stress acting normal to the crack walls $\left(\sigma_{y y}\right)$. Away from the concretion $\sigma_{y y}$ is approximately equal to the theoretical remote stress $\left(\sigma_{y y}^{\mathrm{r}}=10.26 \mathrm{MPa}\right)$. This crackdriving stress is on the same order of that reported for joint propagation elsewhere (e.g. Segall and Pollard, 1983).

FRANC automatically remeshes elements in the vicinity of the joint, increasing the model resolution of the near-crack stress field. Crack-tip singularities are simulated using rosettes of eight quadratic, triangular, isoparametric quarter-point elements (after Barsoum, 1976). After solving for the initial displacements and associated stresses, the joint was then made to propagate toward the concretion in a series of discrete usercontrolled increments. Increment size was scaled to the characteristic size of the mesh in the region into which the crack-tip was to move. For each increment of crack propagation, FRANC calculated the crack-tip stress field, determined the crack growth direction using the calculated maximum circumferential stress, and propagated the crack-tip by the specified increment.

The thermoelastic loading conditions produced a crack propagation path that remained perpendicular to 


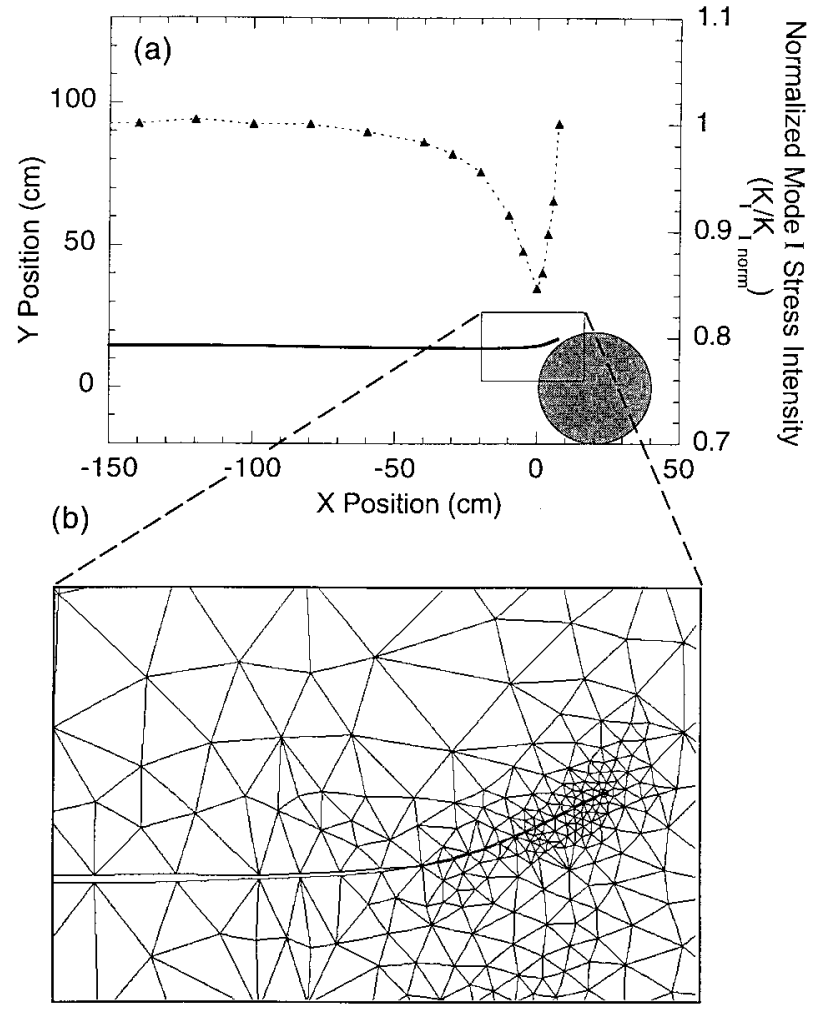

Fig. 6. (a) Crack propagation path (solid line) and normalized Mode I stress intensity for a joint originating $2 \mathrm{~m}$ from the concretion and driven by remote tensile stress $\left(\sigma_{y y}^{\mathrm{r}}=10.26 \mathrm{MPa}\right)$ acting normal to the crack walls. The propagation direction remains perpendicular to $\sigma_{y y}^{\mathrm{r}}$ until the crack-tip is about $10 \mathrm{~cm}$ from the concretion, beyond which point individual crack increments consistently kink upwards (maximum kink angle $=7^{\circ}$ ). Further propagation follows a path that becomes tangent to the perimeter of the concretion. Normalized Mode I stress intensity $\left(K_{\mathrm{I}} / K_{\mathrm{I} \text { norm }}\right)$ decreases from unity as the crack-tip enters a region of reduced tensile stress centered on the $x$ axis. As the crack-tip curves away from the $x$-axis, the normalized stress intensity increases in response to an increase in crack-driving stress. (b) Detail of the crack propagation path showing refinement of finite-element mesh. FRANC's automatic remeshing algorithm reduces element size in the vicinity of the crack-tip as it nears a material interface (the concretion). User-controlled crack increment size is re-scaled with element size, permitting the crack to respond smoothly to local stress perturbations.

the remote stress through nearly $2 \mathrm{~m}$ of crack growth (Fig. 6). From a point about $10 \mathrm{~cm}$ from the concretion the crack-tip began to curve, approaching the concretion tangentially. As the crack-tip approached a material interface (i.e. the concretion), element size was scaled with the distance to the interface, resulting in progressively finer mesh (Fig. 6). Mode I stress intensity $\left(K_{\mathrm{I}}\right)$ at the crack-tip reflects the magnitude of the crack-normal driving stress and the geometry of the crack. In these simulations, $K_{\mathrm{I}}$ was calculated using the J-integral method, and was checked periodically for agreement with $K_{\mathrm{I}}$ calculated by two other methods, displacement correlation and modified crack closure integral (e.g. Bittencourt et al., 1992).
A duplicate simulation was performed using the same mesh and boundary conditions, but with the material properties of the concretion set equal to those of the shale. The joint in the duplicate simulation was required to move through an identical series of cracktip displacements, generating a second set of calculated stress intensities $\left(K_{\mathrm{I} \text { norm }}\right)$. To isolate the effect of the local stress perturbation associated with the concretion from possible edge effects or variations due to the changing size of the crack-tip elements, the stress intensity at each increment of growth was normalized by dividing through by $K_{\text {I norm }}$ (Fig. 6). The normalized Mode I stress intensity decreases from unity as the joint tip passes through a region of reduced crackdriving stress. This is followed by a steep increase in $K_{\mathrm{I}}$ as the crack-tip deflects towards a region of elevated driving stress. Continued growth of the joint results in a propagation path that becomes tangent to the perimeter of the concretion.

The crack propagation path proved insensitive to the magnitude of the extensional strain applied. Model runs with strains $\left(\epsilon_{y}\right)$ of $6.25 \times 10^{-5}$ and $6.25 \times 10^{-3}$, producing remote stresses of 1.03 and $103 \mathrm{MPa}$, respectively, yielded crack paths and normalized stress intensity plots nearly identical to the initial case. Other model runs showed that the amount of curvature of the propagating joint was directly related to the contrast in Young's modulus between the concretion and the shale. A decrease in the contrast (i.e. lowering $E$ for the concretion from 50 to $25 \mathrm{GPa}$ ) resulted in smaller stress perturbations and reduced tendency for the crack to deflect (Fig. 7). Maximum curvature, as indicated by kink angles for individual crack increments, decreased from 7 to $2.6^{\circ}$. Normalized Mode I stress intensity remains close to unity (i.e. the value expected for a crack propagating through a uniform stress field) until the crack-tip is very near to the concretion. Changes in Poisson's ratio for the concretion had little effect on the propagation path of the crack.

Repositioning the initial joint along the $y$-axis influenced the crack propagation path. Joints positioned on the $x$-axis of the concretion $(y=0)$ propagate perpendicularly to $\sigma_{y y}^{\mathrm{r}}$ due to the symmetry of the stress perturbation. When the initial position is shifted to a point aligned with the perimeter of the concretion $(y=20 \mathrm{~cm})$, the crack shows a reduced tendency to curve, re-establishing itself with respect to the remote stress as it moves beyond the influence of the concretion (Fig. 7). Maximum crack path curvature occurs for initial joint positions between 5 and $15 \mathrm{~cm}$ above the $x$-axis.

\subsection{Results: fluid loading}

Evidence points to a depth of about $3 \mathrm{~km}$ for the development of overpressure and the propagation of 

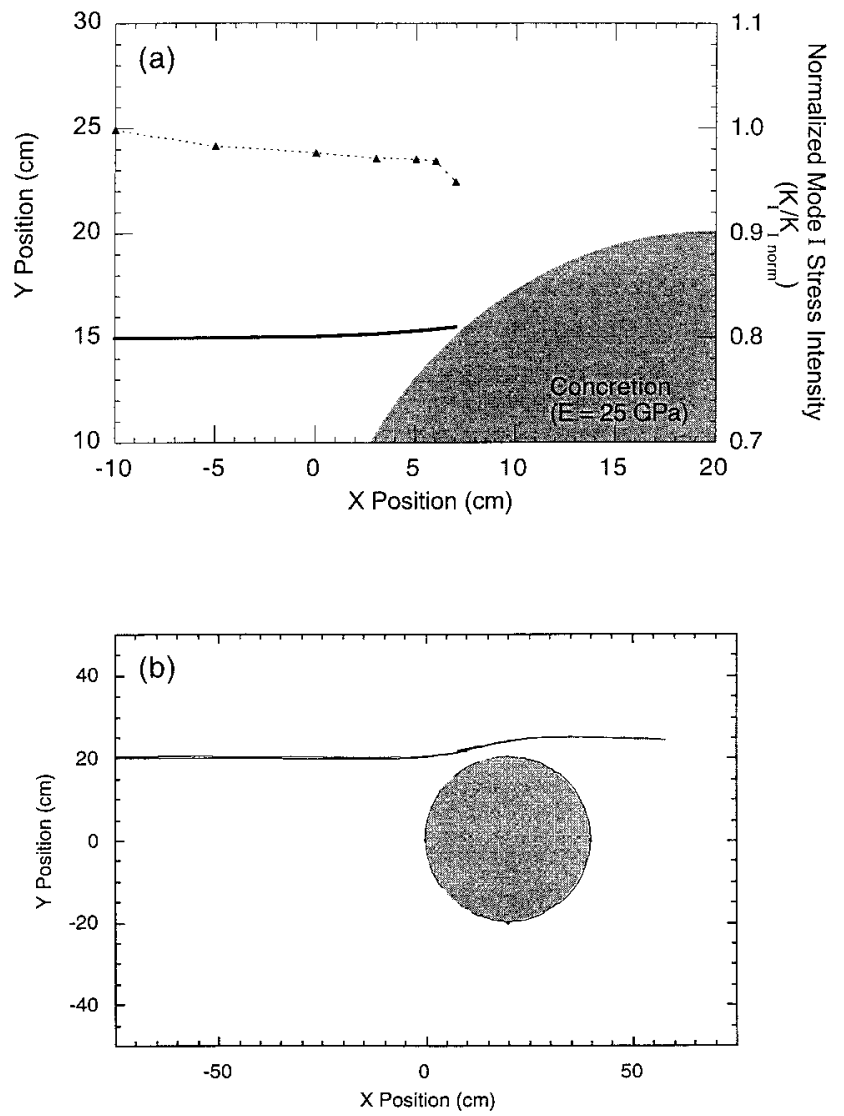

Fig. 7. (a) Crack propagation path (solid line) and normalized stress intensity given a reduced stiffness contrast $\left(E_{\text {concretion }}=25 \mathrm{GPa}\right.$, $\left.E_{\text {shale }}=16 \mathrm{GPa}\right)$ under the same loading conditions as in Fig. 6 $\left(\sigma_{y y}^{\mathrm{r}}=10.26 \mathrm{MPa}\right)$. Maximum kink angle is reduced to less than $3^{\circ}$, and overall deflection of the crack is lessened as the stiffness contrast is reduced. (b) Repositioning of the initial joint upwards along the $y$ axis $(y=20 \mathrm{~cm})$ while using the same elastic properties as in Fig. 6 $\left(E_{\text {concretion }}=50 \mathrm{GPa}, E_{\text {shale }}=16 \mathrm{GPa}\right)$ also results in a crack propagation path with reduced curvature (maximum kink angle $=3.6^{\circ}$ ). The joint reestablishes perpendicularity with respect to the remote stress as it passes beyond the influence of the concretion.

natural hydraulic fractures on the Appalachian Plateau (Engelder and Oertel, 1985; Engelder and Lacazette, 1990; Evans, 1994). The magnitude of the horizontal stress difference $\left(\sigma_{\mathrm{d}}=S_{\mathrm{H}}-S_{\mathrm{h}}\right)$ for this analysis was constrained by two estimates. Analysis of free-face dissolution of crinoid columnals from Upper Devonian rocks of the Appalachian Plateau suggests a lower limit of $6 \mathrm{MPa}$ for $\sigma_{\mathrm{d}}$ (Engelder, 1982). Data from the Wilkins well, South Canisteo, New York, which penetrates the Geneseo Formation, can be extrapolated to $3 \mathrm{~km}$ depth to obtain an upper estimate for $\sigma_{\mathrm{d}}$ of $30 \mathrm{MPa}$ (Evans et al., 1989a). For vertical joints to propagate, the minimum principal stress must be in the horizontal plane $\left(S_{\mathrm{h}}\right)$, whereas the maximum principal stress can be either horizontal $\left(S_{\mathrm{H}}\right)$ or vertical $\left(S_{\mathrm{v}}\right)$.

A second series of models were designed to simulate fluid loading conditions under which natural hydraulic fracture could occur. Contractional strains of $\epsilon_{y}=$ $-3.0 \times 10^{-3}$ and $\epsilon_{x}=-4.0 \times 10^{-3}$ were applied, resulting in model values approximately equal to the theoretical remote stresses for the applied strain and rock properties: $-77.9 \mathrm{MPa}$ parallel to the crack $\left(\sigma_{x x}^{\mathrm{r}}=S_{\mathrm{H}}\right)$, and a remote crack-normal stress $\left(\sigma_{y y}^{\mathrm{r}}=S_{\mathrm{h}}\right)$ of $-64.1 \mathrm{MPa}$. The resulting horizontal stress difference of $13.8 \mathrm{MPa}$ is within the limits given above. The model stresses are assumed to represent total stresses, the combined effects of external loading and the poroelastic response of the rock to fluid pressure.

The presence of a stiff concretion in this compressive environment generated stress perturbations of similar geometry to those produced in the extensional model. However, the region centered on the $x$-axis, outside the concretion, became a zone of reduced crack-normal compressive stress (Fig. 8b). Regions of reduced compressive stress are favored for local joint propagation when internal pore pressure acting against the walls of a joint exceeds the least compressive total stress $\left(P_{\mathrm{p}}>\left|S_{\mathrm{h}}\right|\right)$. In this compressive model environment, the driving stress required for joint propagation is generated by fluid pressure (Secor, 1965):

$\Delta \sigma=\left|P_{\mathrm{p}}\right|-\sigma_{y y}$.

The model assumes both the shale and the concretion to be porous and subject to uniform pore pressure. A $1 \mathrm{~m}$ joint is introduced into this environment and an internal crack pressure $\left(P_{\mathrm{p}}\right)$ of $75 \mathrm{MPa}$ was applied to the joint walls (Fig. 8), generating a crack-driving stress, $\Delta \sigma$, of approximately $10.9 \mathrm{MPa}$ at distance from the concretion. The magnitude of the driving stress varies with $\sigma_{y y}$, which varies with position around the concretion (Fig. 8).

Propagation of the crack under fluid loading conditions produced a joint trace that, like the thermoelastic model, deviated only slightly from its initial plane over the first meter of growth (Fig. 9). As the crack-tip reaches a distance of about $1 \mathrm{~m}$ from the concretion, the joint gradually deflected toward the zone of reduced compressive stress near the $x$-axis of the concretion, attaining an orientation normal to the perimeter as it approached to within a few centimeters of the concretion. The increase in normalized stress intensity reflects the increase in driving stress, $\Delta \sigma$, that occurred as the joint tip moved into the region of reduced compressive stress. A sharp drop in $K_{\mathrm{I}}$ occurred as the crack-tip approached to within a few millimeters of the concretion. As was the case for thermoelastic loading, the propagation path and normalized $K_{\mathrm{I}}$ were insensitive to the magnitude of the applied loads. Also similar to the thermoelastic loading results was the response of the model to the strength of the contrast in the modulus of the two materials. A 

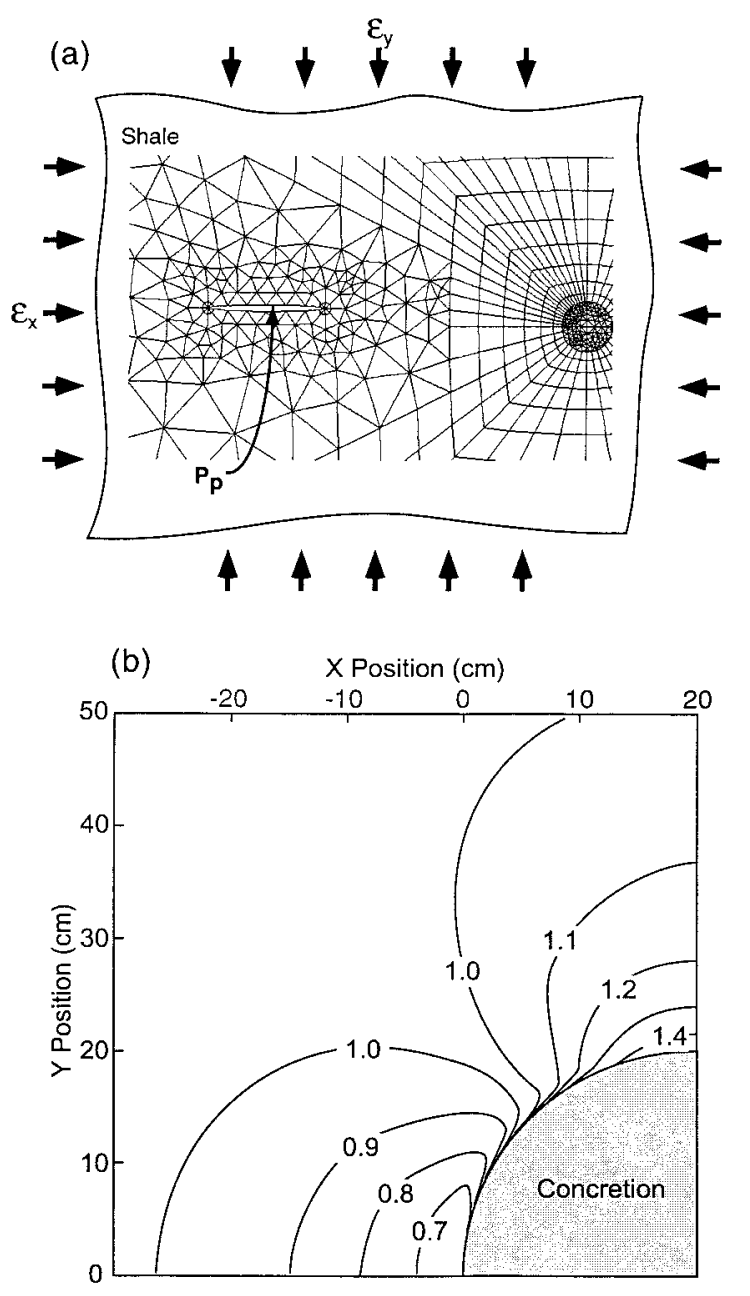

Fig. 8. (a) Loading configuration for fluid-driven joints. The applied strain is contractional in both the $x$ - and $y$-directions $\left(\epsilon_{y}=-3.0 \times 10^{-3} ; \epsilon_{x}=-4.0 \times 10^{-3}\right)$, producing a theoretical remote stress $\left(\sigma_{x x}^{\mathrm{r}}\right)$ of $-77.9 \mathrm{MPa}$ parallel to the crack and a remote cracknormal stress $\left(\sigma_{y y}^{\mathrm{r}}\right)$ of $-64.1 \mathrm{MPa}$. An internal crack pressure $\left(P_{\mathrm{p}}=75 \mathrm{MPa}\right)$ is applied to the walls of the joint, producing a crackdriving stress $(\Delta \sigma)$ of $10.9 \mathrm{MPa}$. (b) Contour map of normalized $\left(\sigma_{y y} / \sigma_{y y}^{\mathrm{r}}\right)$ compressive stress field produced by contractional loading prior to introduction of the joint. The stress shadows along the axes are reversed in nature compared to the extensional model, with regions of elevated compressive stress about the $y$-axis and regions of reduced compressive stress, favorable for propagation of fluid-driven joints, along the $x$-axis.

reduced contrast produced a reduced tendency of the joint to curve. Increasing the horizontal stress difference also reduced the curvature of the crack path. An increase from 13.8 to $30 \mathrm{MPa}\left(\sigma_{x x}-\sigma_{y y}\right)$ resulted in a decrease in total $y$-displacement (initial $y$-positionfinal $y$-position) of approximately $1 \mathrm{~cm}$ for $2 \mathrm{~m}$ of crack growth in the $x$-direction. Large horizontal stress ratios $\left(\sigma_{x x} / \sigma_{y y}>1.5\right)$ caused instabilities in the model.

The two loading configurations, one with and one without pore pressure, produced crack trajectories with opposite senses of curvature, toward the concretion for

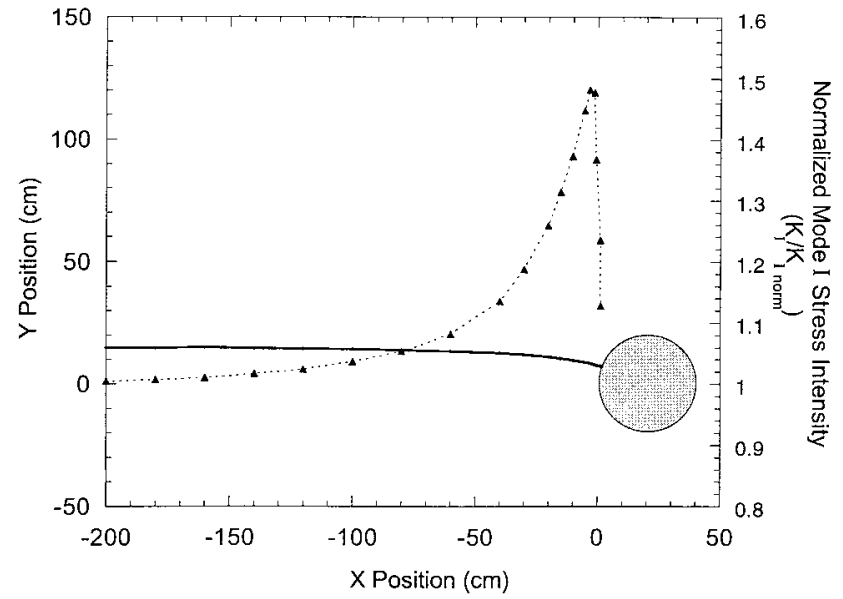

Fig. 9. Crack propagation path (solid line) and normalized Mode I stress intensity for a joint originating $2 \mathrm{~m}$ from the concretion and driven by fluid loading. The stress perturbations associated with the concretion cause the crack to be deflected towards the $x$-axis. This is accompanied by an increase in normalized stress intensity as the crack-tip moves into a region of reduced compressive stress. Normalized $K_{\mathrm{I}}$ decreases sharply as the crack-tip approaches to within a few millimeters of the concretion, an effect caused by the presence of the interface.

fluid-driven jointing, and away from the concretion for thermoelastic loading. The sense of curvature observed for cross joints located near the Squaw Point concretions (Fig. 2) was more accurately reproduced using thermoelastic loading of the model.

\section{Systematic ENE joints}

The planar and continuous nature of the systematic joints suggests that their origin may be relatively far from the concretion. Traces of the ENE joints are aligned on opposite sides of the concretions, suggesting that the joints are larger-scale fractures that propagated through the surrounding shale and were locally arrested at or within a concretion (Fig. 2). There is no observable deflection of these planar joints as they approach a concretion. There are two key questions prompted by the behavior of these joints: Why do the systematic joints fail to curve in response to stress perturbations near the concretion? Why is the propagation of the systematic joints suppressed as they enter a concretion?

Both loading configurations produced joint propagation paths that curved, away from the concretion in the case of thermoelastic loading, and towards the concretion for fluid loading conditions. Neither model is consistent with the observed tendency of the systematic joints to remain in-plane. The explanation may lie in the use of a two-dimensional model in simulating three-dimensional joint propagation. In the field, sys- 
(a)

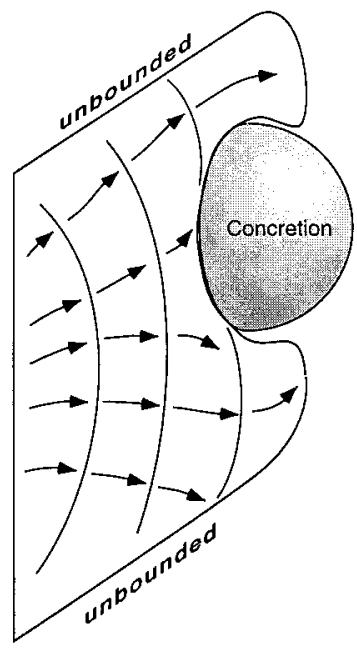

(b)

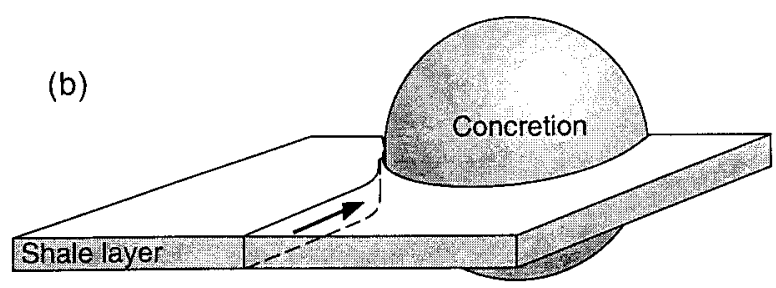

Fig. 10. (a) Unbounded systematic joints commonly have vertical dimensions that exceed the diameter of an embedded concretion. Such joints will tend to propagate in-plane where they interact with a concretion. The presence of the joint in-plane above and below the concretion requires an energetically inefficient breakdown of the crack front in order for curvature near the concretion to occur. (b) Joints that are confined to mechanical layers whose vertical dimension is small compared to that of the concretion are more able to react to local variations in the stress field and may curve as a result. The removal of overburden reduces $S_{\mathrm{v}}$ and thereby reduces the normal compressive stress on horizontal shale parting planes, permitting them to function as mechanical bed boundaries.

tematic ENE joints in massive black shales are unbounded in the vertical direction, having heights the same order of magnitude as their lengths. Thus a systematic joint that encounters a concretion during propagation will tend to be tall relative to the vertical dimension of the concretion. Above and below the concretion, the joint can propagate in-plane, unaffected by the local stress field surrounding the concretion (Fig. 10). Kinking or curving of the leading edge of the joint, in response to the stress perturbations near the concretion, would require an energetically demanding breakdown of the crack front. The joint will instead tend to propagate in-plane, arresting as it interacts with the concretion, producing a joint trace in outcrop in which the joint aligns on opposite sides of the concretion. The two-dimensional model is sensitive to local stress perturbations associated with the concretion, whereas an unbounded (three-dimensional) joint may be constrained by in-plane propagation below

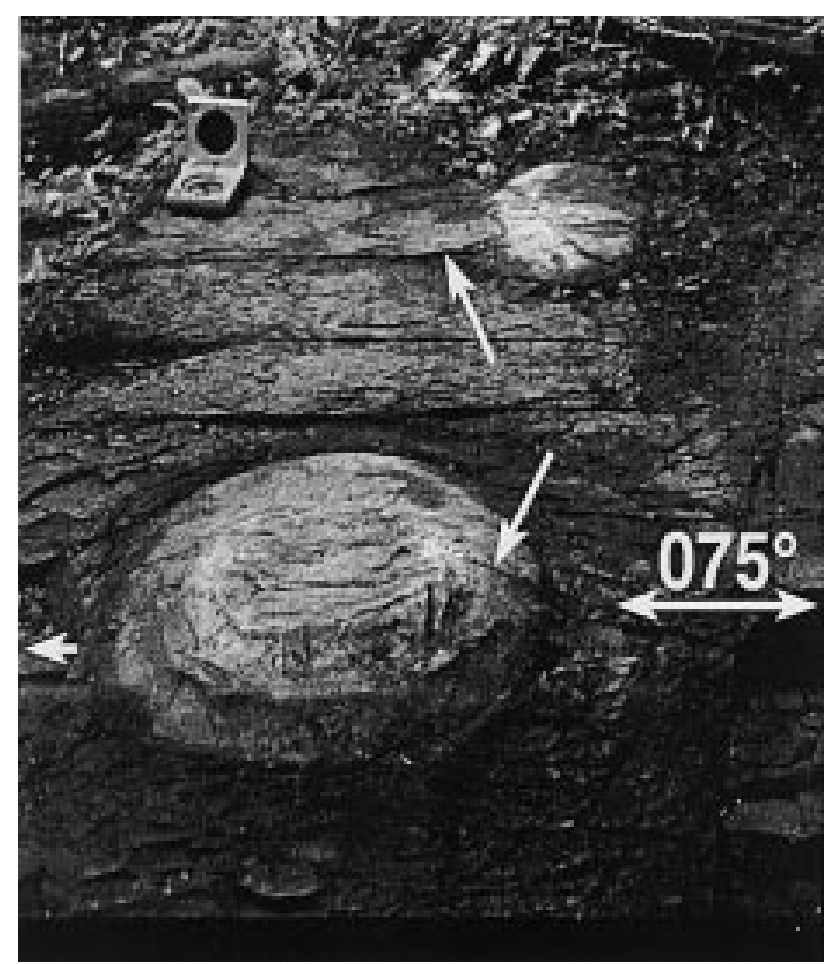

Fig. 11. Photograph of two concretions taken from a direction orthogonal to Fig. 2. The plane of a systematic ENE joint is indicated with a two-headed arrow. This joint can be seen emerging on the opposite side of the concretion. This joint penetrates a few centimeters into a concretion, as does another into the concretion in the background (marked with arrows). The lack of offset of the joints across the interface indicates either strong bonding or high normal compressive stress. Alleghanian cross-fold joints (vertically oriented in the photograph) cleanly cross-cut the systematic ENE joints.

and above the concretion. This interpretation still leaves unanswered the question of why the ENE joints do not propagate through the concretion.

\subsection{Joint propagation through an interface}

Some systematic ENE joints propagated a few centimeters into concretions before arresting (Fig. 11). This phenomenon is observable elsewhere in the outcrop, but only when associated with long planar ENE joints. Traces of these joints commonly align on opposite sides of a concretion, indicating their continuity. The tendency of these to penetrate the interface between the shale and a concretion may provide additional insight into the nature of the joint-driving mechanism. Factors that affect the propagation of the joints across the interface include the strength of the interface, the geometry of the interface, the material properties of the shale vs the concretion, and the loading conditions (Helgeson and Aydin, 1991). Assessing the interface strength is problematic, but because ENE joints crossed the interface without deflection or offset, it seems the interface was either strongly bonded or sub- 


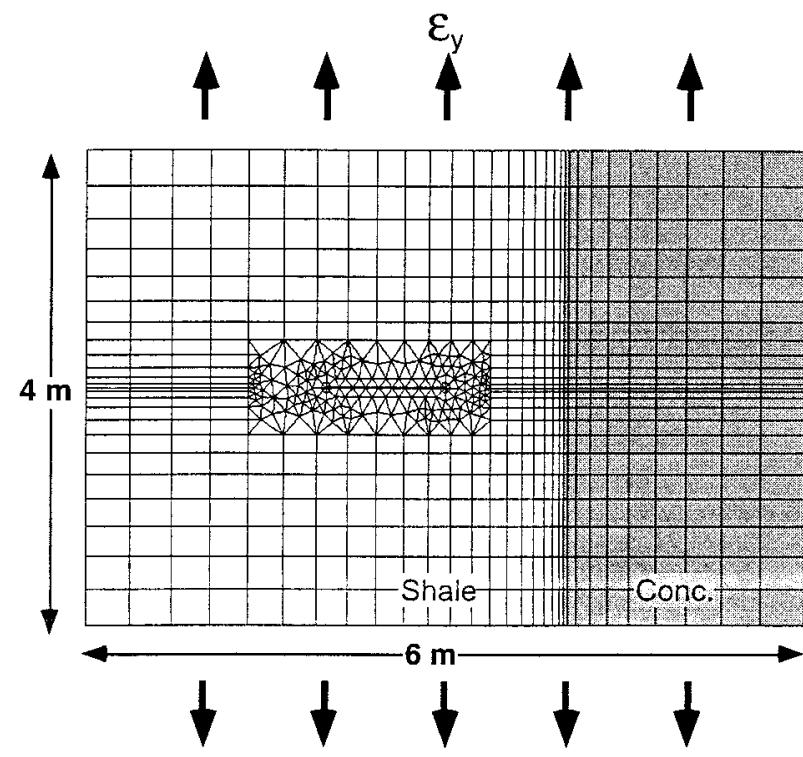

Fig. 12. Model geometry, finite-element mesh, and loading configuration for modeling the propagation of a joint (initial length $=1 \mathrm{~m}$ ) through a bonded interface separating two materials. This configuration permits investigation of the factors controlling the propagation of a systematic joint into a concretion. In this series of models, the theoretical joint normal stress $\left(\sigma_{y y}^{\mathrm{r}}\right)$ is proportional to Young's modulus for the two materials. An extensional strain $\left(\epsilon_{y}\right)$ of $6.25 \times 10^{-4}$ produces a $\sigma_{y y}^{\mathrm{r}}$ of $10.26 \mathrm{MPa}$ in the shale $\left(E_{\text {Shale }}=16 \mathrm{GPa}\right)$ and $14.11 \mathrm{MPa}$ in the concretion $\left(E_{\mathrm{Conc}}=22 \mathrm{MPa}\right)$. These moduli are chosen for the two materials to produce a joint-normal stress $40 \%$ higher in the material into which the joint will be driven, the same stress ratio used in the previous concretion models (e.g. Fig. 4).

ject to high normal compressive stress. Since these joints vary in their angle of intersection with the interface, such that the magnitude of normal stress across the interface would presumably vary, we favor bonding of the interface as an explanation for the observed lack of deflection. A stiff concretion affects the propagation

of a joint as it approaches the concretion from a more compliant shale. Linear elastic fracture theory predicts that for a perfectly bonded interface between ideal materials, stress intensity decreases, and ultimately goes to zero, as a joint subject to tension approaches an interface across which Young's modulus increases (Hilton and Sih, 1971; Erdogan and Biricikoglu, 1973). Unless additional energy is added to the rock-joint system to overcome the decrease in the release of strain energy, the joint will arrest as it approaches an interface. Under thermoelastic loading, once a joint crosses the interface, the strain energy should increase in proportion to the ratio of the moduli, with the maximum increase coinciding with in-plane propagation (Helgeson and Aydin, 1991). Thus we might expect a joint that had begun to fracture the concretion to continue to propagate through it without hesi-

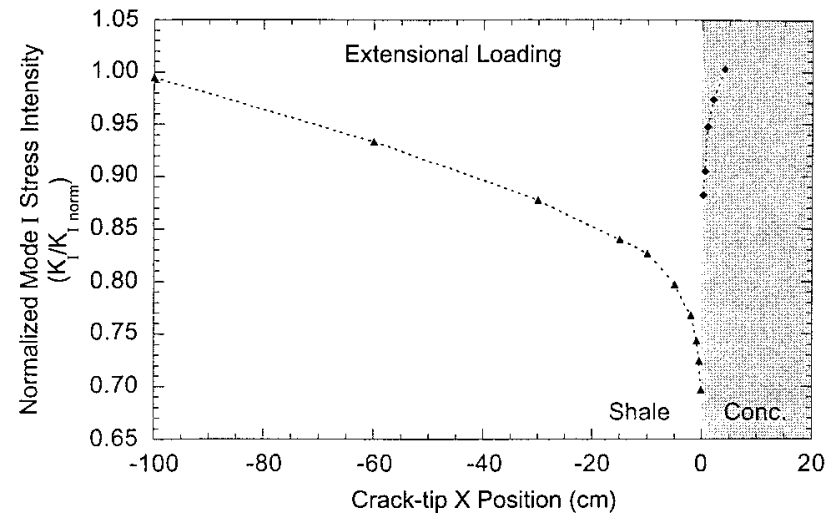

Fig. 13. Normalized Mode I stress intensity for a joint propagating from a lower modulus material into a higher modulus material $\left(E_{\text {Conc }} / E_{\text {Shale }} \cong 1.4\right)$ under extensional loading conditions. The decrease in stress intensity as the joint approaches the interface is consistent with the tendency of many joints to arrest as they approach a concretion. The rapid increase in stress intensity as the joint crosses into a stiffer material (i.e. the concretion) suggests that a joint with sufficient energy to reach the interface should propagate into and through the higher modulus material.

tation or arrest. This is not the case with the systematic ENE joints.

A series of models was designed to investigate the tendency of a joint to arrest or propagate as it crosses an interface into a stiffer elastic material (e.g. a concretion). The Mode I stress intensity at the crack-tip was used as an indicator of the likely behavior of the joint. If a propagating joint experienced an increase in stress intensity, it was expected to continue to propagate. Decreasing stress intensity signaled a tendency of the joint to arrest. A series of joint propagation models were constructed in which a planar joint was driven through an interface between two materials of differing elastic properties. Prior to introduction of the joint, an applied strain produces uniform tensile stress fields in each of the two layers with magnitudes proportional to the moduli of the materials. Young's modulus was initially set at 16 and $22 \mathrm{GPa}$ for the shale and concretion, respectively. The moduli were chosen to approximate the stress contrast produced in the earlier series of models. Since Poisson's ratio had previously been found to have minimal effect on the results, it was left as a constant ( 0.16 for both materials).

To simulate a systematic ENE joint propagating into a concretion under thermoelastic loading conditions, an extensional strain $\left(\epsilon_{y}\right)$ of $6.25 \times 10^{-4}$ was applied at the boundaries of the model, producing a uniform tensile stress $\left(\sigma_{y y}\right)$ of $10.26 \mathrm{MPa}$ within the shale (Fig. 12), and 14.1 MPa within the concretion. A 1 -m-long joint was placed in the more compliant material (shale), and caused to propagate through the interface. We assume a crack-driving stress equal in magnitude to $\sigma_{y y}^{\mathrm{r}}$ is sufficient to drive the joint. Propagation of the joint through an interface with 


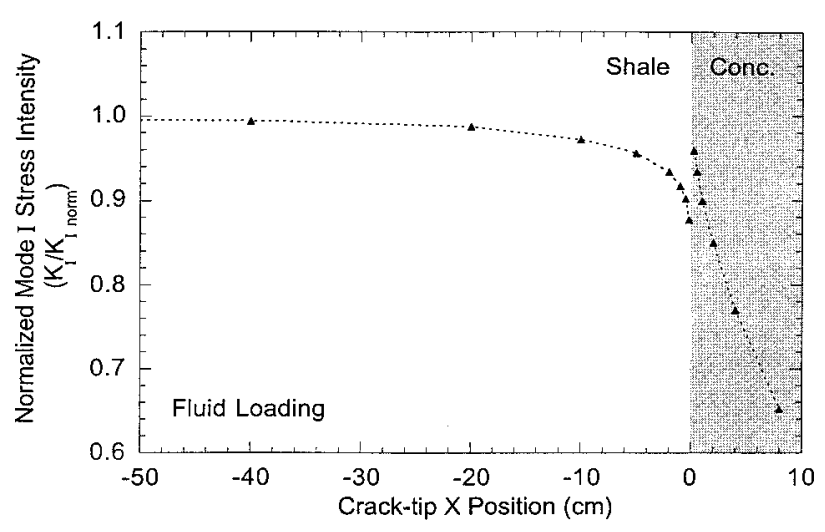

Fig. 14. Normalized stress intensity for a joint driven under fluid loading conditions. The crack-tip experiences a decrease in stress intensity, similar to that of a joint driven by extensional loading (Fig. 13), as the interface is approached. As the interface is crossed, an abrupt increase in stress intensity is followed by a rapid decline, suggesting that a joint driven by fluid loading should arrest after propagating a small distance into the stiffer material.

FRANC was accomplished by using progressively smaller crack increments, and a correspondingly reduced element size (Fig. 12). Mode I stress intensity was normalized using the same procedure described previously (i.e. running a duplicate simulation with identical properties prescribed for the two materials to

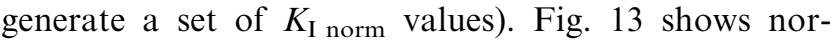
malized Mode I stress intensity vs position of the crack-tip relative to the interface for a crack driven through the interface under thermoelastic loading. Normalized stress intensity begins at 1.0 away from the interface and decreases as the interface is approached. This result is consistent with theoretical predictions for fractures in ideal elastic materials. The model also indicates a sharp increase in stress intensity once the joint crosses the interface and enters the stiffer material.

To simulate natural hydraulic fractures propagating through an interface into higher modulus material, a contractional strain $\left(\epsilon_{y}\right)$ of $4 \times 10^{-3}$ is applied at the boundary, producing a joint-normal compressive stress in the shale equal to the theoretical remote stress $\left(\sigma_{y y}^{\mathrm{r}}\right)$ of $-65.5 \mathrm{MPa}$. In the stiffer material (i.e. the concretion), $\sigma_{y y}^{\mathrm{r}}$ is $40 \%$ higher, $-91.7 \mathrm{MPa}$. An internal crack pressure of $75 \mathrm{MPa}$, applied to the walls of a one meter joint, produces a joint-normal driving stress of approximately $9.5 \mathrm{MPa}$ within the shale. Compared to the result for thermoelastic loading, the decrease in normalized stress intensity is delayed until the cracktip is relatively close to the interface. It appears that less energy is required to drive the joint to the interface under these conditions relative to the joint driven by extension (Figs. 13 and 14). As the crack is driven into the stiffer material, the stress intensity falls rapidly in

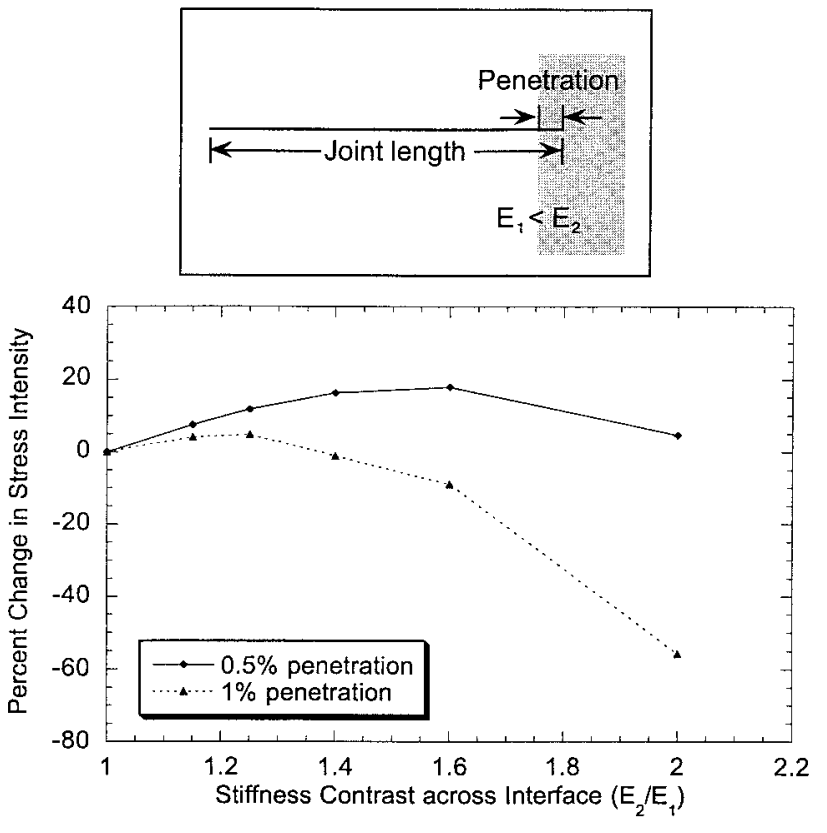

Fig. 15. The percent change in stress intensity as the crack-tip moves into the stiffer material is shown as a function of both stiffness ratio and penetration depth relative to joint length. The results show increases in $K_{\mathrm{I}}$ for small penetration depths over a range of stiffness ratios. Further penetration (i.e. $1 \%$ vs $0.5 \%$ ) results in decreases in $K_{\mathrm{I}}$ for higher stiffness ratios.

response to the increase in crack-normal stress $\left(\sigma_{y y}\right)$ acting against the internal crack pressure.

The results also show an abrupt positive spike in stress intensity as the crack-tip moves into the stiffer material (Fig. 14). This spike appears to be a function of two factors: the stiffness ratio between the materials, and the depth of penetration into the stiffer material relative to the overall joint length. In a series of models the stiffness ratio was varied from $1: 1$ to $3: 1$, and the crack-tip stress intensity calculated for two relative depths of penetration into the stiffer material (Fig. 15). Given a constant internal crack pressure, the percent change in stress intensity from a crack-tip positioned in the interface to a second position within the stiffer material changes with the ratio of Young's modulus for the two materials. For small relative penetration depths, $K_{\mathrm{I}}$ increases as the joint moves into the stiffer material for stiffness ratios up to 2:1. A stiffness ratio of $3: 1$ results in a sufficiently high compressive crack-normal stress to prevent the crack from opening in the stiffer material $\left(K_{\mathrm{I}}=0\right)$. For a given material stiffness ratio, $K_{\mathrm{I}}$ decreases as the depth of penetration is increased (Fig. 15), thus we expect deeper penetration of the joint for more similar materials.

The results demonstrate that joints driven under the two loading configurations may behave very similarly as they approach an interface across which stiffness increases. In both cases the decrease in stress intensity as the crack-tip approaches the interface may cause 
the joint to arrest. For joints with sufficient energy to cross the interface, the modeling suggests that the behavior should differ depending on the loading configuration. Under thermoelastic loading the joint should propagate through the stiffer material due to a rapid increase in stress intensity. Under fluid loading, joints may propagate a small distance into the stiffer material, driven by the abrupt increase in $K_{\mathrm{I}}$ as the interface is crossed, but should subsequently arrest within the concretion as the stress intensity decreases. Under the same conditions, longer joints, such as the systematic ENE joints, would be more likely to penetrate into the stiff concretions than the shorter cross joints.

The stress intensities calculated from this simple model most likely have very limited applicability for simulating the complex interactions at the crack-tip, particularly those very near the interface. The results are primarily intended to demonstrate the inconsistency of the observed behavior of these joints with loading due to thermoelastic contraction.

\section{Discussion}

\subsection{Loading configurations}

Our models confirm that joint propagation is sensitive to two of the loading configurations proposed by Engelder and Fischer (1996). Under both loading configurations, a concretion-generated stress perturbation causes out-of-plane joint propagation in the vicinity of a concretion provided joint height is limited to the diameter of the concretion. The direction of deflection is indicative of the type of loading configuration. Thermoelastic loading produced joints that curved away from the center of the concretion (Fig. 6), whereas fluid loading of a joint in a compressive environment caused the joint to curve towards the center of the concretion as it propagated (Fig. 9). Although two-dimensional modeling of the systematic ENE joints subject to fluid load predicted a tendency to curve near the concretions, this characteristic is not observed in the outcrop. We interpret this as indicative of the unbounded nature of the systematic joints that remained in-plane as they propagated around the concretions.

A necessary condition for the formation of curvy cross joints near the concretion is that they propagate while confined to layers that are thin with respect to the vertical dimension of the concretion (Fig. 10). A decrease in vertical stress associated with removal of overburden may have permitted the development of layer-parallel parting planes within the black shale. Weakly bonded interfaces such as parting planes have been demonstrated to serve as effective barriers to frac- ture growth when normal stress across the interface is low (e.g. in the near surface) (Teufel and Clark, 1984; Warpinski and Teufel, 1987). These parting planes appear to have served as bounding surfaces during the propagation of the vertical cross joints.

In the outcrop, the sense of deflection observed for cross joints was away from the center of the concretion (Fig. 2), consistent with a thermoelastic model. Where they are not strongly influenced by stress perturbations such as those associated with the concretions or preexisting joints, cross joints propagate in an orientation that is roughly parallel to the present day maximum compression direction (Zoback and Zoback, 1991; Engelder and Gross, 1993). This evidence, coupled with their tendency to abut systematic Alleghanian joints, suggests that cross joints propagate in the contemporary stress field as late-stage joints. The driving mechanism for cross joints is thermoelastic contraction due to unloading during exhumation of the Appalachian Plateau in the Late Tertiary (Hancock and Engelder, 1989; Blackmer et al., 1994).

\subsection{Interface penetration}

A key characteristic of joint-concretion interaction is that neither systematic ENE joints nor cross joints propagate through the central portion of the larger concretions. All cross joints arrest at the interface between the shale and the concretion whereas some systematic ENE joints propagate a small distance into the concretion. Arrest at or near the boundary clearly demonstrates that these joints did not originate within the concretions. Otherwise joints that initiate inside the concretions would propagate through the relatively homogeneous stress field generated within the concretion by either loading configuration. Modeling suggests that stress intensity falls as a joint approaches an inclusion of stiffer material for both the thermoelastic and fluid loading conditions (Figs. 13 and 14). Thus, increased energy is required to drive the joint to the interface in either case. Once the joint reaches the interface, however, the energy requirements for further propagation vary with loading configuration. The increase in stress intensity experienced by a joint driven by thermoelastic loading suggests that the joint should propagate completely through the concretion. A fluid driven joint may experience an increase in stress intensity immediately upon entering the concretion, but the model suggests that it should soon arrest, as $K_{\mathrm{I}}$ decreases dramatically toward the central portion of the concretion (Fig. 15). Researchers investigating hydraulic fracture containment have documented this tendency in experimentally induced hydraulic fractures and numerical models (Simonson et al., 1978; Warpinski et al., 1982; Teufel and Clark, 1984; Warpinski and Teufel, 1987). They found that high 
modulus layers may not consistently stop a propagating fracture at the interface, but tended to restrict its growth. The dominant factor in fracture containment was found to be stress contrast. Fracture growth was confined effectively by regions of higher stress. The applied loading conditions in this study generate stress contrasts by virtue of the differences in modulus between the concretion and the surrounding shale. At depths where the total stress is compressive, higher joint-normal stresses in the concretion inhibit growth of the joint.

\subsection{Fluid loading history}

The clastic rocks of the Appalachian Plateau contain a complex network of cross-cutting and abutting joints (e.g. Parker, 1942; Helgeson and Aydin, 1991; Engelder and Gross, 1993; Younes and Engelder, 1999). The first set to appear is the systematic ENE joints (Engelder et al., submitted). This set of joints is found in gray and black shales of the Catskill Delta complex, but only in those located stratigraphically beneath the Rhinestreet Formation, a postulated pressure seal (Albrecht, 1992). The restricted distribution of these joints to rocks beneath a pressure seal suggests that they formed at depth, in a compressive environment where fluid pressure is most likely required to generate effective tensile stresses. Our model for the joint-concretion interaction indicates a loading configuration that confirms this earlier judgment. The ENE joints are parallel to nearby joints and veins in the Lockport Formation that are interpreted as Acadian (Gross et al., 1992). If so, they propagated during burial of the black shale in the prograding Catskill Delta Complex sometime during the Devonian. The most likely mechanism for overpressuring at this time would have been compaction disequilibrium. The systematic ENE joints are cross-cut by Alleghanian joints suggesting that overpressure was maintained from Devonian burial through Alleghanian compression.

We know more about fluid loading during the Alleghanian joint propagation. Perhaps the most convincing evidence for high-pressure fluid loading during fracture propagation is the near-lithostatic trapping pressure of fluid inclusions in mineralized joints of the Appalachian Plateau (Lacazette, 1991; Evans, 1995). Even in these structures, we only know that the mineralized joint was once filled with high-pressure fluid, but the role of the fluid decompression in joint propagation can only be inferred. Additional evidence consistent with natural hydraulic fracturing by fluid decompression is the incremental growth of joints indicated by a fan-like pattern of plumose morphology on Alleghanian joints in siltstone beds of the Catskill Delta complex (Lacazette and Engelder, 1992). The postulate that high fluid pressure did exist at the time of joint propagation is supported by the presence of undercompacted shales in the Devonian section, indicated by shale density profiles (Albrecht, 1992), compaction of flocculated clays estimated from preferred orientation of chlorite (Engelder and Oertel, 1985; Evans et al., 1989a), and the anisotropy of magnetic susceptibility (Hirt et al., 1995). Likewise, the distribution of volume loss strain by pressure solution, as indicated by field observations (Engelder, 1979, 1984) and by modeling the chlorite fabric (Evans et al., 1989a), and the poroelastic relaxation of pore pressure inferred from the present in situ stress profile (Evans et al., 1989b), add further support to the high fluid pressure scenario.

\section{Conclusions}

Concretions like those found at Squaw Point functioned mechanically as stiffer inclusions in the more compliant matrix of black shale. Loading of the rock produced local perturbations in the stress field surrounding the concretions that influenced joint propagation paths. The curved propagation paths of some cross joints near concretions are indicative of thermoelastic loading conditions during their formation. The general orientation of the cross joints is consistent with the contemporary stress field, suggesting that they developed as late-stage, unloading joints driven by thermoelastic loading.

The planar nature and alignment of the systematic ENE joints on opposite sides of concretions indicates that they formed in a regional stress field. They propagated in-plane above and below the concretion, making it energetically inefficient for the crack front to curve as it interacted with the concretion. The interface between concretions and the surrounding shale was strongly bonded, as evidenced by the crossing of the interface by some fractures. Higher compressive stress levels within the concretions relative to the shale suppressed joint development, causing those joints that were driven across an interface into a concretion to arrest. Our modeling suggests that the tendency for the ENE joints to propagate across the interface into a concretion before arresting is inconsistent with thermoelastic loading conditions. A fluid-drive mechanism is therefore proposed for the development of the ENE joints. Their formation is attributed to fluid pressure during pre-Alleghanian stages of burial of the Devonian Catskill delta complex.

\section{Acknowledgements}

Discussions with Staci Loewy, Laura Silliphant, and 
Amgad Younes were particularly helpful in directing our ideas for this paper. Support for this work came from funds of the Penn State Seal Evaluation Consortium (SEC). We thank David Sanderson and Richard Lisle for their effort in reviewing this paper.

\section{References}

Albrecht, W., 1992. Geochemistry of diagenetic pressure seal formation. PhD thesis, Pennsylvania State University.

Barsoum, R.S., 1976. On the use of isoparametric elements in linear elastic fracture mechanics. International Journal of Numerical Methods in Engineering 10, 25-37.

Bittencourt, T.N., Barry, A., Ingraffea, A.R., 1992. Comparison of mixed-mode stress intensity factors obtained through displacement correlation, J-integral formulations, and modified crack closure integral. In: Atluri, S.N., Newman Jr., J.C., Raju, I.S., Epstein, J.S. (Eds.), Fracture Mechanics 22 Symposium. American Society of Testing and Materials Special Technical Publication 1131, vol. 2, pp. 69-82.

Blackmer, G.C., Omar, G.I., Gold, D.P., 1994. Post-Alleghanian unroofing history of the Appalachian Basin, Pennsylvania, from apatite fission track analysis and thermal models. Tectonics 13, 1259-1276.

Engelder, T., 1979. The natural deformation within the outer limits of the central Appalachian foreland fold and thrust belt in New York State. Tectonophysics 55, 289-310.

Engelder, T., 1982. A natural example of the simultaneous operation of free-face dissolution and pressure solution. Geochimica et Cosmochimica Acta 46, 69-74.

Engelder, T., 1984. The role of pore water circulation during the deformation of foreland fold and thrust belts. Journal of Geophysical Research 89, 4319-4325.

Engelder, T., Fischer, M.P., 1996. Loading configurations and driving mechanisms for joints based on the Griffith energy-balance concept. Tectonophysics 256, 253-277.

Engelder, T., Geiser, P., 1980. On the use of regional joint sets as trajectories of paleostress fields during the development of the Appalachian Plateau, New York. Journal of Geophysical Research 85, 6319-6341.

Engelder, T., Gross, M., 1993. Curving cross joints and the neo-tectonic stress field in eastern North America. Geology 21, 817-820.

Engelder, T., Lacazette, A., 1990. Natural hydraulic fracturing. In: Barton, N., Stephannson, O. (Eds.), Rock Joints. A. A. Balkema, Rotterdam, pp. 35-44.

Engelder, T., Oertel, G., 1985. Correlation between abnormal pore pressure and tectonic jointing in the Devonian Catskill Delta. Geology 13, 863-866.

Erdogan, F., Biricikoglu, V., 1973. Two bounded half planes with a crack going through the interface. International Journal of Engineering Science 11, 745-766.

Eshelby, J.D., 1957. The determination of the elastic stress field of an ellipsoidal inclusion, and related problems. Royal Society of London Proceedings 241, 376-395.

Ettensohn, F.R., 1985. The Catskill Delta complex and the Acadian Orogeny: A model. In: Woodrow, D.L., Sevon, W.D. (Eds.), The Catskill Delta. Geological Society of America Special Paper 201, pp. 39-49.

Evans, K.F., Engelder, T., Plumb, R.A., 1989a. Appalachian Stress Study 1: A detailed description of in situ stress variations in Devonian Shales of the Appalachian Plateau. Journal of Geophysical Research 94, 1729-1754.

Evans, K.F., Oertel, G., Engelder, T., 1989b. Appalachian stress study 2: Analysis of Devonian Shale core: some implications for the nature of contemporary stress variations and Alleghanian deformation in Devonian rocks. Journal of Geophysical Research 94, 7155-7170.

Evans, M.A., 1994. Joints and décollement zones in the Middle Devonian shales: Evidence for multiple deformation events in the central Appalachian Plateau. Geological Society of America Bulletin 106, 447-460.

Evans, M.A., 1995. Fluid inclusions in veins from Middle Devonian shales: A record of deformation conditions and fluid evolution in the Appalachian Plateau. Geological Society of America Bulletin 107, 327-339.

Fischer, M.P., 1994. Application of linear elastic fracture mechanics to some problems of fracture propagation in rock and ice. $\mathrm{PhD}$ thesis, Pennsylvania State University.

Fischer, M.P., Gross, M.R., Engelder, T., Greenfield, R.J., 1995. Finite-element analysis of the stress distribution around a pressurized crack in a layered medium: implications for the spacing of fluid-driven joints in bedded sedimentary rock. Tectonophysics 247, 49-64.

Gross, M.R., Engelder, T., Poulson, S., 1992. Veins in the Lockport Dolomite: Evidence for an Acadian fluid circulation system. Geology 20, 971-974.

Hancock, P.L., Engelder, T., 1989. Neotectonic Joints. Geological Society of America Bulletin 101, 1197-1208.

Helgeson, D.E., Aydin, A., 1991. Characteristics of joint propagation across layer interfaces in sedimentary rocks. Journal of Structural Geology 13, 897-911.

Hilton, D., Sih, G.C., 1971. A laminate composite with a crack normal to the surface. International Journal of Solids and Structures 7, 913-930.

Hirt, A.M., Evans, K.F., Engelder, T., 1995. Correlation between magnetic anisotropy and fabric for Devonian shales on the Appalachian Plateau. Tectonophysics 247, 121-132.

Lacazette, A., Engelder, T., 1992. Fluid-driven cyclic propagation of a joint in the Ithaca siltstone, Appalachian Basin, New York. In: Evans, B., Wong, T.-F. (Eds.), Fault Mechanics and Transport Properties of Rock. Academic Press, London, pp. 297-324.

Lacazette, A., 1991. Natural hydraulic fracturing in the Bald Eagle sandstone in Central Pennsylvania and the Ithaca siltstone at Watkins Glen, New York. PhD thesis, Pennsylvania State University.

Lachenbruch, A.H., 1961. Depth and spacing of tension cracks. Journal of Geophysical Research 66, 4273-4292.

Miller, T.W., 1995. New insights into natural hydraulic fractures induced by abnormally high pore pressures. American Association of Petroleum Geologists Bulletin 79, 1005-1018.

Nickelsen, R.P., 1979. Sequence of structural stages of the Allegheny orogeny at the Bear Valley Strip Mine, Shamokin, Pennsylvania. American Journal of Science 279, 225-271.

Oertel, G., Curtis, C.D., 1972. Clay-ironstone concretion preserving fabrics due to progressive compaction. Geological Society of America Bulletin 83, 2597-2606.

Parker, J.M., 1942. Regional systematic jointing in slightly deformed sedimentary rocks. Geological Society of America Bulletin 53, 381-408.

Pollard, D.D., Segall, P., 1987. Theoretical displacements and stresses near fractures in rock: with applications to faults, joints, veins, dikes, and solution surfaces. In: Atkinson, B. (Ed.), Fracture Mechanics of Rock. Academic Press, Orlando, pp. 227350.

Secor Jr., D.J., 1965. Role of fluid pressure in jointing. Journal of Science 263, 633-646.

Sheldon, P., 1912. Some observations and experiments on joint planes. Journal of Geology 20, 53-70.

Simonson, E.R., Abou-Sayed, A.S., Clifton, R.J., 1978. Containment of massive hydraulic fractures. Society of Petroleum Engineers Journal 18, 27-32. 
Teufel, L.W., Clark, J.A., 1984. Hydraulic fracture propagation in layered rock: Experimental studies of fracture containment. Society of Petroleum Engineers Journal 24, 19-32.

Warpinski, N.R., Teufel, L.W., 1987. Influence of geologic discontinuities on hydraulic fracture propagation. Journal of Petroleum Technology 27, 209-220.

Warpinski, N.R., Schmidt, R.A., Northrop, D.A., 1982. In-situ stresses: The predominant influence on hydraulic fracture containment. Journal of Petroleum Technology 34, 653-664.

Wawrzynek, A., Ingraffea, A.R., 1987. Interactive finite element analysis of fracture processes: An integrated approach Theoretical and Applied Fracture Mechanics 8, 137-150.

Younes, A., Engelder, T., 1999. Fringe cracks: Key structures for the interpretation of progressive Alleghanian deformation of the Appalachian Plateau. Geological Society of America Bulletin 111, 219-239.

Zoback, M.D., Zoback, M.L., 1991. Tectonic stress field of North America and relative plate motions. In: Slemmons, D.B., Engdahl, E.R., Zoback, M.D., Blackwell, D.D. (Eds.), Neotectonics of North America, Boulder. Geological Society of America, Decade Map Volume 1, pp. 339-366. 